\title{
Impact of agricultural waste on the shrink-swell behavior and cracking dynamics of expansive soils
}

\author{
Siviwe Odwa Malongweni ${ }^{1} \cdot$ Yasutaka Kihara $^{1} \cdot$ Kuniaki Sato $^{1} \cdot$ Takeo Tokunari $^{2} \cdot$ Tabhorbayar Sobuda $^{2}$. \\ Kaya Mrubata ${ }^{3} \cdot$ Tsugiyuki Masunaga $^{1}$
}

Received: 21 November 2018 / Accepted: 11 April 2019 / Published online: 26 April 2019

(c) The Author(s) 2019

\begin{abstract}
Purpose The swelling characteristics and cracking of expansive clayey soils usually lead to their low yield, and as a result, large areas of expansive soils remain uncultivated and unproductive. There is a need for the development of simple, low-cost technologies which will bring these soils into production. The amendment of expansive clayey soils with agricultural waste products is a key goal for enhancing their production potential. Therefore, a study was conducted to evaluate the ameliorative effects of crop residues on the physiochemical and mechanical properties of expansive clayey soils.

Method In this study, the potential soil amendments used include uncharred rice husk, rice husk biochar, uncharred sugarcane bagasse, and sugarcane bagasse biochar. The biochar was pyrolyzed at $450{ }^{\circ} \mathrm{C}$. The amendments were applied into the soil at four applications rates: $0,2,5$, and $10 \%$ by weight of soil (w/w), respectively. The mixture was then incubated in a glasshouse for 280 days.

Results Charred and uncharred rice husk and sugarcane bagasse improved the physico-mechanical properties related to soil expansion. The liquid limit (LL), plastic limit (PL), plasticity (PI), coefficient of linier extensibility (COLE core ), volumetric shrinkage (VS), fissures' dimensions, and crack area density (CAD) of the soil decreased with an increase in treatment application rate. On the contrary, saturated water content increased with an increase in dosage.

Conclusions $10 \%$ level of amendment application resulted in significantly improved soil properties than either $2 \%$ or $5 \%$ doses. Moreover, $2 \%$ level of amendment application is more preferable than 5\% according to feasibility and economic point of view.
\end{abstract}

Keywords Rice husk · Sugarcane bagasse · Expansion · Amendment · Biochar · Uncharred

\section{Introduction}

In general, partially saturated fine-grained soils having high plasticity are very sensitive to changes in moisture content and show excessive volume changes (Sarkar et al. 2012). Such soils are classified as expansive soils and they attribute their characteristics to the presence of swelling clay (smectite) minerals. As they get wet, the clay minerals absorb water and expand, thus becoming muddy and sticky; conversely, as they dry they shrink, thus, becoming hard and forming desiccation cracks along the surface of the soil (Pal 2016; Elias et al. 2001). Soil cracks are of critical

Tabhorbayar Sobuda b-so@meiwa-ind.co.jp

Kaya Mrubata mrubatak@arc.agric.za

1 Faculty of Life and Environmental Sciences, Shimane University, Matsue, Japan

2 Meiwa Kogyo Co. Ltd, Kanazawa, Japan

3 Agricultural Research Council Institute of Soil, Climate and Water, Pretoria, South Africa 
importance in a variety of circumstances. They allow for an enhanced water entry into the soil. They also have a capacity to enhance rapid flow of nutrients in the subsoil. Moreover, the opening and closing of cracks causes a sort of selfmulching (Mokhtari and Dehghani 2012; Taboada 2003). However, despite all these advantages, cracking still destroys the integrity of expansive soils and poses serious problems for crop production (Elias et al. 2001). For instance, soil cracks may cause physical damage to plant roots, encourage the vertical movement and leaching of dissolved nutrients beyond root zone, provide extra surface for moisture loss, and they may even promote rill erosion. Because of all these problems caused by cracking, crop production on shrink-swell soils is limited (Wubie 2015).

The shrink-swell potential of expansive soils can potentially be mitigated by mixing and/or replacing existing expansive soil with non-expansive soil (Mokhtari and Dehghani 2012). However, this technique is destructive and disruptive to the environment, and it does not provide a possible solution to minimize or perhaps fix the issue of clay swelling. Moreover, it can be extremely costly and labor intensive. Therefore, there is a need for the development and utilization of simple and low-cost field techniques which will ameliorate expansion and minimize crack formation, thus bringing these soils into production. Zong et al. (2014) and Rama Subbarao et al. (2011) claim that organic materials such as crop residues and biochar have potential to be used as innovative soil amendments for ameliorating expansion, cracking, and other poor physical properties of expansive soils. For instance, Zong et al. (2014) discovered that the addition of wheat straw, woodchips, and rice husk biochar increased the optimum moisture content, shrinkage limit, and unconfined compressive strength, and reduced the swelling potential, liquid limit, plasticity index, and maximum dry density of the soil by altering the physiochemical properties of the soil which are related to soil expansion.

Organic materials such as crop residues and biochar are carbon (C)-based compounds, and they can minimize soil expansion and the formation of cracks by interacting with clay minerals responsible for soil expansion (Husain et al. 2014). Zong et al. (2014) claims that the interactions of organic $\mathrm{C}$ with soil minerals change bond strength and surface tension properties of the soils, thus reducing shrink-swell potential of the soil which, in turn, causes a decrease in crack formation. Nwajiaku et al. (2018) reported that raw material and biochar exhibited completely different chemical properties in rice husk and sugarcane bagasse. These changes in chemical properties of the materials may alter the soil physiochemical properties. Therefore, research is needed to determine the impact of various types of organic materials on the shrink-swell phenomenon and cracking dynamics of clayey soils. This study is aimed at providing a better understanding of the impact of organic waste towards the shrink-swell behavior and cracking dynamics of expansive soils as well as to gain a deeper insight into the factors controlling soil expansion. To fulfill this aim, an experiment was conducted to investigate the short-term (280 days) effect of agricultural wastes towards the physical and mechanical properties related to soil expansion by specifically addressing: (1) the effect of varying amounts of rice husk and sugarcane bagasse (raw material and biochar) applications towards the plastic behavior and cracking dynamics of expansive clayey soils, (2) the impact of varying amounts of rice husk and sugarcane bagasse (raw material and biochar) applications towards the soil properties related to soil expansion, and (3) the possible mechanisms by which organic residues affect soil expansion.

\section{Materials and methods}

\section{Soil and amendment materials}

Natural soil samples $(0-25 \mathrm{~cm})$ were collected from the Kawatsu region located in Shimane prefecture, Japan. The studied soil was an inceptisol as classified according to the USDA classification system. The soil was then air-dried and pulverized manually using a $2 \mathrm{~mm}$ sieve to obtain uniform particle size. Later on, it was thoroughly mixed with two different types of organic wastes. The organic waste materials used in this study include rice husk and sugarcane bagasse produced in Japan. These two agricultural residues were selected because of their low density over a wide range of moisture contents, coupled with small pore size, large surface area, aromatic structure, and high permeability which make them very suitable as potential amendments for improving the soil physicochemical properties related to soil expansion. Moreover, literature review shows that rice husk and sugarcane are major crops in the world (Leff et al. 2004). As a result, they can be easily accessible to many farmers. Furthermore, approximately 134 million tons of rice husk and 54 million tons of bagasse are produced annually in the world, of which over $90 \%$ are burned in open air or discharged into rivers and oceans to dispose of them (Quispe et al. 2017). Therefore, the use of rice husk and sugarcane bagasse as soil amendments can also help to reduce environmental pollution. The organic waste materials were applied into the soil in a form of biochar and in a form of raw material, respectively. The biochar was produced using a batch-type biomass carbonization plant (model ECO500, Meiwa Co., Ltd, Japan) at a pyrolysis temperature of $450{ }^{\circ} \mathrm{C}$ based on the recommendation of Crombie et al. (2013). 


\section{Incubation experiment}

An incubation experiment was conducted to evaluate the impact of charred and uncharred rice husk and sugarcane bagasse on the behavior of expansive clayey soil. The required quantum of study soil $(3 \mathrm{~kg})$ was thoroughly mixed with the agricultural amendments at four rates of application which include $0 \%$ (control), 2, 5, and 10\% (w/w), respectively. The mixture was then placed in plastic pots measuring approximately $20 \mathrm{~cm}$ in depth and $25 \mathrm{~cm}$ in breadth. The experimental design was a randomized complete block design (RCBD) with three replications. The pots were moistened with distilled water to field capacity and incubated at room temperature $\left(27^{\circ} \mathrm{C}\right)$ for 280 days in the Shimane University experimental glasshouse (N35 $29.245^{\prime}$; E133004.129'). The incubated pots were also watered constantly every 5 days according to the water loss to maintain constant moisture content. Soil moisture content was assessed by a soil moisture sensor (type of equipment, DeltaT Devices Ltd. Cambridge). After incubation, the soil samples were air-dried and ground passed through a $2 \mathrm{~mm}$ sieve for subsequent analysis.

\section{Analysis}

Laboratory tests were carried out on the soil under study to determine the following:

\section{Atterberg limits}

The effect of the amendment materials on the swelling potential and consistency behavior of expansive clayey soils was determined by the evaluation of Atterberg limits. The consistency limits were determined by the ASTM D4318 procedure as described by Arbaaz et al. (2015), whereby the plastic limit (PL) was determined using the standard threadrolling method and the liquid limit (LL) was analyzed using the casagrande liquid limit device. The plasticity index (PI) was calculated as the difference between the liquid limit and plastic limit (PI = LL-PL).

\section{Coefficient of linear extensibility (COLE)}

Volumetric change was assessed with coefficient of linear extensibility (COLE) and volumetric shrinkage (VS). $\mathrm{COLE}_{\text {core }}$ was determined according to the Grossman et al. (1968) method. In brief, previously air-dried and sieved $(<2 \mathrm{~mm})$ soil samples were used for $\mathrm{COLE}_{\text {core }}$ measurement. For each sample, soil cores $\left(100 \mathrm{~cm}^{3}\right.$ in volume) were saturated by capillarity and later brought to field capacity $(-33 \mathrm{kPa})$ by allowing excess water to drain. Afterwards, the soil cores were weighed to determine weight and volume. The soil cores were then oven-dried and weight and volume measurements determined again. The change in bulk density from field capacity to the oven-dry state is $\mathrm{COLE}_{\text {core }}$, and it was calculated using the following equation:

$\operatorname{COLE}_{\text {core }}=\left(\frac{\mathrm{Db}_{\text {dry }}}{\mathrm{Db}_{\text {wet }}}\right)^{1 / 3}-1$,

where $\mathrm{Db}_{\text {dry }}$ is bulk density of the oven-dry sample $\left(\mathrm{g} / \mathrm{cm}^{3}\right)$ and $\mathrm{Db}_{\text {wet }}$ is bulk density of the sample at field capacity (g/ $\mathrm{cm}^{3}$ ).

\section{Volumetric shrinkage (VS)}

Volumetric shrinkage (VS) was calculated using the $\mathrm{COLE}_{\text {core }}$ value; the formula is as follows:

$\mathrm{VS}=\left(\mathrm{COLE}_{\text {core }}+1\right)^{3}-1$

\section{Cracking dynamics}

Cracking characteristics of soils were determined using slurry specimens which have been prepared using a soil:deionized water ratio of 1 as suggested by Zong et al. (2014). For each treatment, the soil slurry was poured into a flat rectangular container that has a width of $19.5 \mathrm{~cm}$ and a base length of $30 \mathrm{~cm}$. The containers containing the prepared soil slurries were then allowed to air dry under a constant temperature $27^{\circ} \mathrm{C}$. A digital camera was used to photograph the soil cracks and the final crack pattern. The cracking pattern of the captured images was simulated by converting the raw images displaying soil cracks into binary images using the software adobe Photoshop CC 2017.

Raw images were also processed and quantitatively analyzed using image analysis technique. Image editor software was used for image processing and SigmaScan Pro 5 was used to quantify crack patterns. During the quantification of the soil cracking pattern, Eq. 3 was used to determine crack area density $(\mathrm{CAD})$ :

$\mathrm{CAD}=\frac{\text { surface area of all cracks }}{\text { total surface area of the soil }} 100 \%$.

The cracking pattern has also quantified through the determination of fissures' dimensions whereby the mean length and width of cracks was directly measured from the dried slurry specimen and presented in $\mathrm{cm}$ using a measuring tape (Elias et al. 2001).

\section{Saturated moisture content}

During the determination of saturated moisture content, soil cores $\left(100 \mathrm{~cm}^{3}\right.$ in volume) were saturated by capillarity for $24 \mathrm{~h}$ and later allowed to drain excess water for 
approximately less than an hour. Then, the gravimetric water content of the saturated soils was determined by drying at $105{ }^{\circ} \mathrm{C}$ in an oven for $24 \mathrm{~h}$, and the saturated moisture content was later calculated and presented in percentage terms using the following equation:

$\theta_{\mathrm{g}}=\frac{m_{\mathrm{wet}}-m_{\mathrm{dry}}}{m_{\mathrm{dry}}}=\frac{m_{\mathrm{water}}}{m_{\mathrm{soil}}}$,

where $M_{\text {wet }}(g)$ is the weight of wet soil, $M_{\text {dry }}(g)$ and $\mathrm{M}_{\text {soil }}$ ( $g$ ) is the weight of oven-dried soil, and $M_{\text {water }}(g)$ is the weight of water contained in the saturated soil.

\section{Statistical analysis}

Statistical analysis was performed using SPSS version 25.0. The data were reported as means and standard deviation (SD) of the means. Analysis of variance was used to determine the statistical significance of charred and uncharred agricultural waste residue effects on the shrink-swell behavior and surface cracking characteristics of expansive clayey soils. In cases of significant differences between the mean values, Tukey's test was used.

\section{Results and discussion}

\section{Characteristics of soil and amendment materials}

Table 1 lists the basic properties of the studied soil and agricultural residues. In general, the soil was slightly acidic (pH 5.64), exhibited slight to medium plasticity characteristics $(\mathrm{PI}=14.88)$, and it had low levels of total organic carbon $(0.96 \%)$ and total nitrogen $(0.09 \%)$, which is typical for soils in humid tropical regions such as Japan (Elgamal et al. 2017). The soil also had a low effective cation exchange capacity (ECEC) which might be the result of low organic matter content $(\mathrm{TC}<1 \%)$. Organic matter has negatively charged sites that attract and hold cations, and thus, an increase in organic matter content results in an increase in CEC and vice versa (Zong et al. 2014).

Charred residues of rice husk and sugarcane bagasse had extremely high $\mathrm{pH}$ and EC as compared to uncharred residues. Specifically, the $\mathrm{pH}$ and $\mathrm{EC}$ of rice husk increased from 7.82 and $51.95 \mathrm{mS} / \mathrm{m}$ for uncharred biomass to 10.58 and $64.1 \mathrm{mS} / \mathrm{m}$ after pyrolysis at $450{ }^{\circ} \mathrm{C}$, and it increased from 4.00 and $8.97 \mathrm{mS} / \mathrm{m}$ for uncharred sugarcane biomass residue to 30.85 and $54.5 \mathrm{mS} / \mathrm{m}$ after pyrolysis at $450{ }^{\circ} \mathrm{C}$ (Table 1). This increase in biochar $\mathrm{pH}$ and $\mathrm{EC}$ might be associated with the dehydration of the crop residues and a progressive loss of acidic surface groups during thermal
Table 1 Physical and chemical properties of the studied soil and amendment materials

\begin{tabular}{llllll}
\hline Properties & Soil & \multicolumn{2}{l}{ Amendment material } & \\
\cline { 3 - 6 } & & $\begin{array}{l}\text { Uncharred } \\
\text { rice husk }\end{array}$ & Rice husk biochar & $\begin{array}{l}\text { Uncharred sug- } \\
\text { arcane bagasse }\end{array}$ & $\begin{array}{l}\text { Sugarcane } \\
\text { bagasse } \\
\text { biochar }\end{array}$ \\
\hline $\mathrm{pH}\left(\mathrm{H}_{2} \mathrm{O}, 1: 2.5\right)$ & 5.64 & 7.82 & 10.58 & 4.00 & 8.97 \\
$\mathrm{EC}\left(\mathrm{H}_{2} \mathrm{O}, 1: 5\right)(\mathrm{mS} / \mathrm{m})$ & 14.56 & 51.95 & 64.1 & 30.85 & 54.5 \\
Sand $(\%)$ & 49.18 & - & - & - & - \\
Silt $(\%)$ & 26.83 & - & - & - & - \\
Clay $(\%)$ & 23.99 & - & - & - & - \\
Plasticity index $(\%)$ & 14.88 & - & - & - & - \\
TN $(\%)$ & 0.09 & 0.31 & 0.34 & 0.29 & 0.44 \\
TC $(\%)$ & 0.96 & 35.77 & 39.55 & 39.05 & 59.46 \\
C/N & 10.67 & 115.39 & 116.32 & 134.66 & 135.14 \\
Ash content $(\%)$ & - & 12.65 & 39.48 & 1.82 & 9.25 \\
Surface area $\left(\mathrm{m}^{2} / \mathrm{g}\right)$ & - & & 268.66 & - & 28.79 \\
ECEC $\left(\mathrm{cmol}_{\mathrm{c}} / \mathrm{kg}\right)$ & 8.63 & - & - & - & - \\
Exc. Ca $\left(\mathrm{cmol}_{\mathrm{c}} / \mathrm{kg}\right)$ & 4.33 & 1.78 & 3.05 & 2.33 & 3.13 \\
Exc. $\mathrm{Mg}\left(\mathrm{cmol}_{\mathrm{c}} / \mathrm{kg}\right)$ & 1.85 & 1.11 & 0.94 & 0.39 & 1.52 \\
Exc. K $\left(\mathrm{cmol}_{\mathrm{c}} / \mathrm{kg}\right)$ & 0.26 & 2.88 & 2.43 & 1.52 & 1.80 \\
Exc. $\mathrm{Na}\left(\mathrm{cmol}_{\mathrm{c}} / \mathrm{kg}\right)$ & 1.76 & 0.27 & 0.40 & 0.15 & 0.16 \\
Exc. Acidity $\left(\mathrm{cmol}_{\mathrm{c}} / \mathrm{kg}\right)$ & 0.43 & - & - & - & - \\
\hline & & & & & - \\
\hline
\end{tabular}

$E C$ electrical conductivity, $T N$ total nitrogen, $T C$ total carbon, $E C E C$ effective cation exchange capacity, Exc. $\mathrm{Ca}$ exchangeable $\mathrm{Ca}, E x c . M g$ exchangeable $\mathrm{Mg}, E x c . K$ exchangeable K, Exc. $\mathrm{Na}$ exchangeable Na, Exc. Acidity exchangeable acidity 
treatment (Yuan et al. 2011). Moreover, several authors claim that the reason why $\mathrm{pH}$ and $\mathrm{EC}$ was high for biochar is because, with pyrolysis, the content of carbonates in biochar increases and the content of organic anions on the biochar surface decreases (Liu et al. 2018, Venegas et al. 2015). An increase in carbonate content contributes to the alkalinity of biochar (Yuan et al. 2011). Since uncharred biomass is less alkaline than charred biomass, it would not have a negative impact on crops and soil organisms and can be safely used to improve the quality of soils. On the other hand, the use of biochar may be suitable for improving acid soils.

Table 1 also indicates that organic amendments derived from rice husk had higher ash content than those derived from sugarcane bagasse. This could be due to the higher amount of Si in rice husk (El-gamal et al. 2017). Si is a major component in the chemical structure of rice. The amount of total carbon (TC) for amendment materials derived from sugarcane bagasse was greater than that of rice husk. Moreover, charred biomass had higher TC than uncharred biomass (Table 1). El-gamal et al. (2017) and Bottino and Cunha-Santino (2016) declare that the higher amount of TC for sugarcane bagasse may be attributed to the high content of cellulose and hemicellulose. Exchangeable cations of the biochar were all higher than those of the uncharred material (Table 1). These results were consistent with those described by Jien and Wang (2013), who distinctly proclaims that the high specific surface area (SSA) of the biochar might be the reason for the higher concentration of exchangeable cations. A high SSA causes an increase in the number of negatively charged sites that attracts and holds positively charged particles.

\section{Atterberg limits}

The effect of charred and uncharred rice husk and sugarcane bagasse amendments on Atterberg limits (LL, PL, and PI) of the investigated expansive clayey soil is presented in Table 2. The original soil had an LL of 37.82, a PL of 22.94, and a PI of $14.88 \%$, which makes it a medium plastic soil according to the plasticity categories proposed by Sowers (1979). After being amended with rice husk and sugarcane bagasse residues at various application rates, the Atterberg limits of the soil tend to change.

The effect of amendment material on soil LL was variable among the four kinds of amendment materials (Table 2). Despite these variations, it can be seen that the LL significantly $(p<0.05)$ increased with the application of treatment into the soil. Moreover, the effect of sugarcane bagasse was more pronounced compared to the control and rice husk. After the addition of amendment materials, the LL significantly $(p<0.05)$ increased from $37.82 \%$ for the control to as high as $42.07,39.42,46.62$, and $44.36 \%$ for rice husk biochar, uncharred rice husk, sugarcane bagasse biochar, and uncharred sugarcane bagasse amendments, respectively. The increased values of LL indicate that more water will be required to turn the "soil-amendment material" mix to fluid (Rama Subbarao et al. 2011). This can be considered as a consequence of substituting soil particles by the more
Table 2 Impact of charred and uncharred rice husk and sugarcane bagasse on Atterberg limits (LL, PL, and PI) of the investigated expansive clayey soil

\begin{tabular}{|c|c|c|c|c|}
\hline \multirow[t]{2}{*}{ Amendment material } & \multirow{2}{*}{$\begin{array}{l}\text { Application rate } \\
(\%)\end{array}$} & \multicolumn{3}{|l|}{ Atterberg limits } \\
\hline & & $\begin{array}{l}\text { Liquid limit (LL, } \\
\%)\end{array}$ & $\begin{array}{l}\text { Plastic limit (PL, } \\
\%)\end{array}$ & $\begin{array}{l}\text { Plasticity } \\
\text { index (PI, } \\
\%)\end{array}$ \\
\hline \multirow[t]{4}{*}{ Uncharred rice husk } & Control & $37.82^{\mathrm{b}}$ & $22.94^{c}$ & $14.88^{\mathrm{a}}$ \\
\hline & $2 \%$ & $37.83^{\mathrm{b}}$ & $24.04^{\mathrm{bc}}$ & $13.79^{\mathrm{ab}}$ \\
\hline & $5 \%$ & $39.42^{\mathrm{a}}$ & $26.04^{\mathrm{a}}$ & $13.38^{\mathrm{ab}}$ \\
\hline & $10 \%$ & $37.78^{\mathrm{b}}$ & $25.06^{\mathrm{ab}}$ & $12.72^{\mathrm{b}}$ \\
\hline \multirow[t]{4}{*}{ Rice husk biochar } & Control & $37.82^{\mathrm{d}}$ & $22.94^{\mathrm{c}}$ & $14.88^{\mathrm{a}}$ \\
\hline & $2 \%$ & $42.07^{\mathrm{a}}$ & $28.49^{\mathrm{a}}$ & $13.58^{\mathrm{ab}}$ \\
\hline & $5 \%$ & $39.07^{\mathrm{b}}$ & $27.46^{\mathrm{ab}}$ & $11.61^{\mathrm{b}}$ \\
\hline & $10 \%$ & $38.52^{\mathrm{c}}$ & $25.43^{\mathrm{b}}$ & $13.09^{\mathrm{ab}}$ \\
\hline \multirow[t]{4}{*}{ Uncharred sugarcane bagasse } & Control & $37.82^{\mathrm{d}}$ & $22.94^{\mathrm{b}}$ & $14.88^{\mathrm{a}}$ \\
\hline & $2 \%$ & $39.77^{\mathrm{c}}$ & $27.21^{\mathrm{ab}}$ & $12.56^{\mathrm{a}}$ \\
\hline & $5 \%$ & $40.29^{\mathrm{b}}$ & $28.28^{\mathrm{b}}$ & $12.01^{\mathrm{a}}$ \\
\hline & $10 \%$ & $44.36^{\mathrm{a}}$ & $29.03^{\mathrm{b}}$ & $15.33^{\mathrm{a}}$ \\
\hline \multirow[t]{4}{*}{ Sugarcane bagasse biochar } & Control & $37.82^{\mathrm{c}}$ & $22.94^{\mathrm{c}}$ & $14.88^{\mathrm{a}}$ \\
\hline & $2 \%$ & $36.41^{\mathrm{d}}$ & $23.09^{c}$ & $13.32^{\mathrm{ab}}$ \\
\hline & $5 \%$ & $46.62^{\mathrm{a}}$ & $34.03^{\mathrm{a}}$ & $12.59^{\mathrm{ab}}$ \\
\hline & $10 \%$ & $42.25^{\mathrm{b}}$ & $30.41^{\mathrm{b}}$ & $11.84^{\mathrm{b}}$ \\
\hline
\end{tabular}

Means with different letter in the same column are significantly different $(p<0.05)$ 
porous biochar and decomposed residues of rice husk and sugarcane bagasse (Jien and Wang 2013; Rama Subbarao et al. 2011). Biochar and decomposed crop residues have high water retention capacity, and they act like a sponge, thus, absorbing and holding large volumes of water and leaving a limited amount of moisture to be absorbed and held by the clay particles responsible for soil expansion. This, then, delays the transition of soil from the plastic state to the liquid state, and, hence, the increase in LL. These results were consistent with those described by Rama Subbarao et al. (2011), who found that the LL of the soil was significantly increased by $45.4 \%$ and $53.9 \%$ with the addition of $4 \%$ and $12 \%$ rice husk biochar.

The variations in PL value were similar to those of $L L$ in the sense that the PL was significantly $(p<0.05)$ increased when the soil was amended with 2,5 , and $10 \%$ uncharred and charred rice husk and sugarcane bagasse, respectively (Table 2). After being treated with $10 \%$ rice husk and sugarcane residues and biochar, the PL of soil significantly $(p<0.05)$ increased by $8.46,9.79,20.98$, and $24.56 \%$ for uncharred rice husk, charred rice husk, uncharred sugarcane bagasse, and sugarcane bagasse biochar amended soils, respectively. The reason for the variations in PL is similar to that of LL.

With regards to the PI, it can be defined as the moisture contents at which the soil exhibits plastic properties (Andrade et al. 2011). Based on Table 2, the PI of the soil decreased with an increase in application rate for all the amendments, with the exception of $10 \%$ uncharred sugarcane bagasse, indicating that rice husk and sugarcane bagasse have the potential to ameliorate soil expansion. The PI significantly $(p<0.05)$ decreased by $14.52,12.03$, and $20.43 \%$ for the soil treated with $10 \%$ uncharred rice husk, charred rice husk, and sugarcane bagasse biochar, respectively. This is because the used amendments are nonplastic materials and they do not show any plastic behavior. With increase in percentage of non-plastic material in the soil, the PI of "soil-amendment material" mix will decrease (Rama Subbarao et al. 2011).

The mechanisms explaining the effects of biochar and uncharred treatments on soil plasticity are also related to the dynamics of water in the surface pore system of the used materials (Conte and Laudicina 2017; Zong et al. 2014). For instance, the decomposed residues of the uncharred treatment and biochar act as a coating agent (glue effect) that coats the clay particles responsible for swelling, such that when water is added into the soil, it first reacts with the porous and spongy amendment material before coming into contact with the expanding clay minerals. A large quantity of water will, therefore, be absorbed by the amendment material, thus, leaving a limited amount of water to penetrate the inter-layer space of expanding clay minerals present in the soil. Therefore, this mechanism minimizes soil expansion by minimizing the interaction of water with the expanding clay minerals. Furthermore, biochar and organic matter of the decomposed residues of the uncharred material might also have pores inside of their particles (intra-pores), which may provide additional space for water storage beyond the pore space between their particles (inter-pores) (Zaffar et al. 2017; Rama Subbarao et al. 2011).

Despite the decrease in PI, the effect of $2 \%$ application rate was less pronounced than other application levels (5\% and $10 \%$ ) for all the four used treatments. This is probably due to the very low doses used during the course of the experiment. A significant $(p<0.05)$ decrease in soil consistency was observed at the highest application rate (10\%) which means that a higher dose of the amendment material is needed to prevent or reduce soil expansion. It can also be noted that, when the soil was amended with rice husk biochar, a significant $(p<0.05)$ decrease in PI occurred at the treatment application rate of $5 \%$, but not at $10 \%$. A clear understanding of reasons for this behavior is not yet understood.

\section{Coefficient of linear extensibility (COLE)}

The coefficient of linear extensibility $\left(\mathrm{COLE}_{\text {core }}\right)$ is the measure of the capacity of the soil to swell when wet, and to shrink and crack when dry (Zong et al. 2014; Taboada 2003). The $\mathrm{COLE}_{\text {core }}$ values of studied soil are displayed in Fig. 1. The $\mathrm{COLE}_{\text {core }}$ value of the original expansive clayey soil was 0.049 , corresponding to the moderate shrink-swell hazard category when using the soil shrink-swell classes proposed by Taboada (2003).

The application of the amendment material significantly $(p<0.05)$ decreased the $\mathrm{COLE}_{\text {core }}$ value for all the treatments (Fig. 1). The $\mathrm{COLE}_{\text {core }}$ value decreased from 0.049 in control to $0.034,0.036,0.029$, and 0.030 with $10 \%$ rice husk biochar, uncharred rice husk, sugarcane bagasse biochar, and uncharred sugarcane bagasse amendments, respectively. Reduction in $\mathrm{COLE}_{\text {core }}$ was more pronounced for the soils amended with uncharred sugarcane bagasse, as the amendment material significantly $(p<0.05)$ decreased the $\mathrm{COLE}_{\text {core }}$ value by $28.57,37.69$, and $40.82 \%$ for the 2,5 , and $10 \%$ application rates, respectively. These results are consistent with the previous findings of Zong et al. (2014) who found that the addition of $6 \%$ wheat straw and woodchip biochar into clayey soil drastically decreased the $\mathrm{COLE}_{\text {core }}$ value.

The introduction of amendments reduced the $\mathrm{COLE}_{\text {core }}$ and, thus, the shrinkage and swelling hazard by altering the clay minerals responsible for the shrinkage and swelling properties of soil (Zaffar et al. 2017). Several authors claim that the particles of biochar and decomposed crop residues may cover clay mineral phase surfaces and settle in the pore spaces among the soil particles, which then cause 
Fig. 1 Impact of charred and uncharred rice husk and sugarcane bagasse on the coefficient of linear extensibility (COLE) of the investigated expansive clayey soil. The error bars in the figure represent standard error. Different letters above the bars of each treatment indicate significant difference $(p<0.05)$

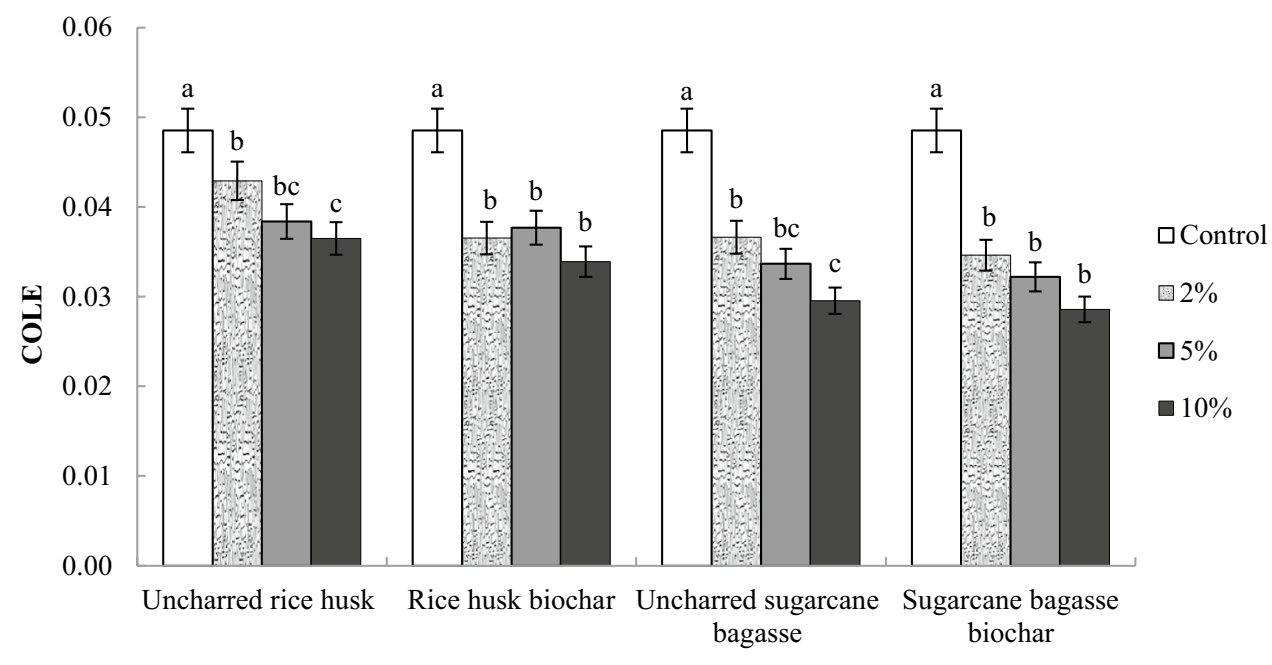

Amendment material a significant reduction in swelling potential of the soil and, thus, lowering the $\mathrm{COLE}_{\text {core }}$ value (Rama Subbarao et al. 2011). Another cause for the decrease in $\mathrm{COLE}_{\text {core }}$ value may be due to the influence of carbon (C) particles of the amendments on clay minerals responsible for shrinkage and swelling (Zong et al. 2014). When the $C$ particles interact with clay colloids, they form a clay-C complex. The clay-C complexes may influence the behavior of particles at a colloidal level, which cause a significant change at the microstructural level and affect soil swell-shrinkage properties (Zong et al. 2014; Liu et al. 2012).

Based on Fig. 1, a significant $(p<0.05)$ decrease in the $\mathrm{COLE}_{\text {core }}$ was observed between the lowest and the highest (2\% and $10 \%)$ application rate for uncharred rice husk and uncharred sugarcane bagasse amendments. For the soil amended with biochar treatments, there were no significant $(p<0.05)$ differences between 2 and $10 \%$ application rates. This implies that biochar application rates used were too narrow to bring about significant changes in the $\mathrm{COLE}_{\text {core }}$ value, and therefore, biochar needs to be applied at higher application rates that are wide apart in order for it to cause significant changes in the $\mathrm{COLE}_{\text {core }}$ value.

\section{Volumetric shrinkage (VS)}

The effect of amendments on volumetric shrinkage (VS) is demonstrated in Fig. 2. VS of the soil decreased with increasing amendment application rate. Percentage VS of the original soil was $15.28 \%$. After $10 \%$ treatment addition, the VS of soil significantly $(p<0.05)$ decreased to 11.35 , $10.52,9.13$, and $8.82 \%$ for uncharred rice husk, charred rice husk, uncharred sugarcane bagasse, and sugarcane bagasse
Fig. 2 Impact of charred and uncharred rice husk and sugarcane bagasse on volumetric shrinkage of the investigated expansive clayey soil. The error bars in the figure represent standard error. Different letters above the bars of each treatment indicate significant difference $(p<0.05)$

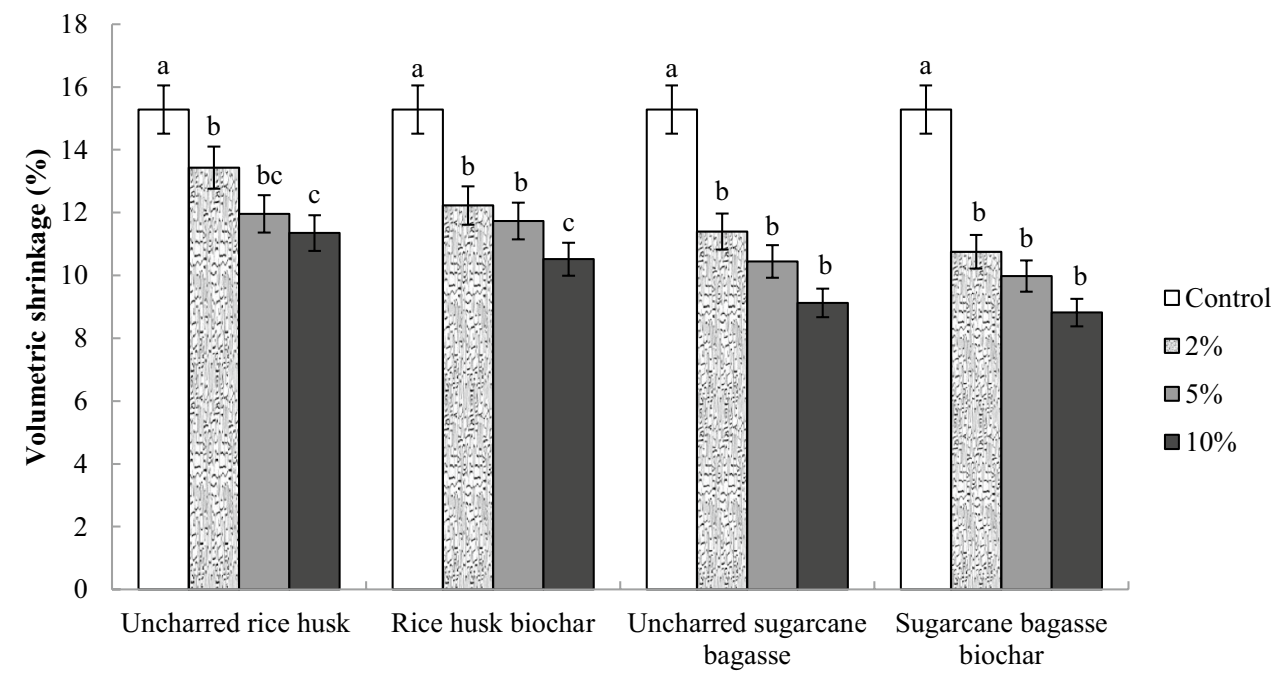

Amendment material 
biochar amended soils, respectively. Moreover, reduction in VS was more evident for the soil amended with treatments derived from sugarcane bagasse. The reason for the significant decrease in VS is also similar to that of $\mathrm{COLE}_{\text {core }}$.

\section{Soil cracking pattern}

Morphological observations on the pattern of cracking development in the incubation experiment are displayed in Table 3. They indicate that the application of uncharred and charred agricultural residues influence the initiation and propagation of desiccation cracks in the expansive soil being investigated.

Based on Table 3, the addition of uncharred and charred rice husk and sugarcane bagasse into the soil has markedly reduced the prominence and size of shrinkage cracks. In the control soil, the desiccation cracks were large and wide, and they also started to appear earlier than in amended soils. On the other hand, the shrinkage cracks of the amended soil samples were small and thin. All things considered, and the prominence and size of shrinkage cracks decreased with increase in application rate. Changes in the initiation and propagation of shrinkage cracks are due to the decrease in

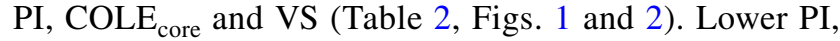
$\mathrm{COLE}_{\text {core }}$, and VS values surely cause a reduction the overall size and prominence of desiccation cracks by minimizing the shrink-swell potential of the soil. The results displayed in Table 3 are consistent with those described by Zong et al. (2014), who found that the application of biochar affects the formation of distribution of shrinkage cracks in clayey soils. Zong et al. (2014) state that changes in the intensity and thickness of desiccation cracks in biochar amended soils are an indication of improvement in soil aggregation.

\section{Crack area density (CAD)}

Crack area density (CAD) can be defined as the summation of cracks area and shrinkage area in a specimen (Zong et al. 2014). From Table 4, it can be clearly observed that the areas of soil cracks were markedly reduced by the application of rice husk and sugarcane bagasse amendments into the soil.

The CAD of the soil was initially $12.68 \%$. After the application of the amendment material, the CAD value decreased with increasing treatment application rate. The application of $10 \%$ amendment material significantly $(p<0.05)$ decreased CAD by $39.98 \%$ for uncharred rice husk, $61.83 \%$ for rice

Table 3 Morphological observations of the cracking pattern (surface cracks) in the expansive soil amended with charred and uncharred rice husk and sugarcane bagasse

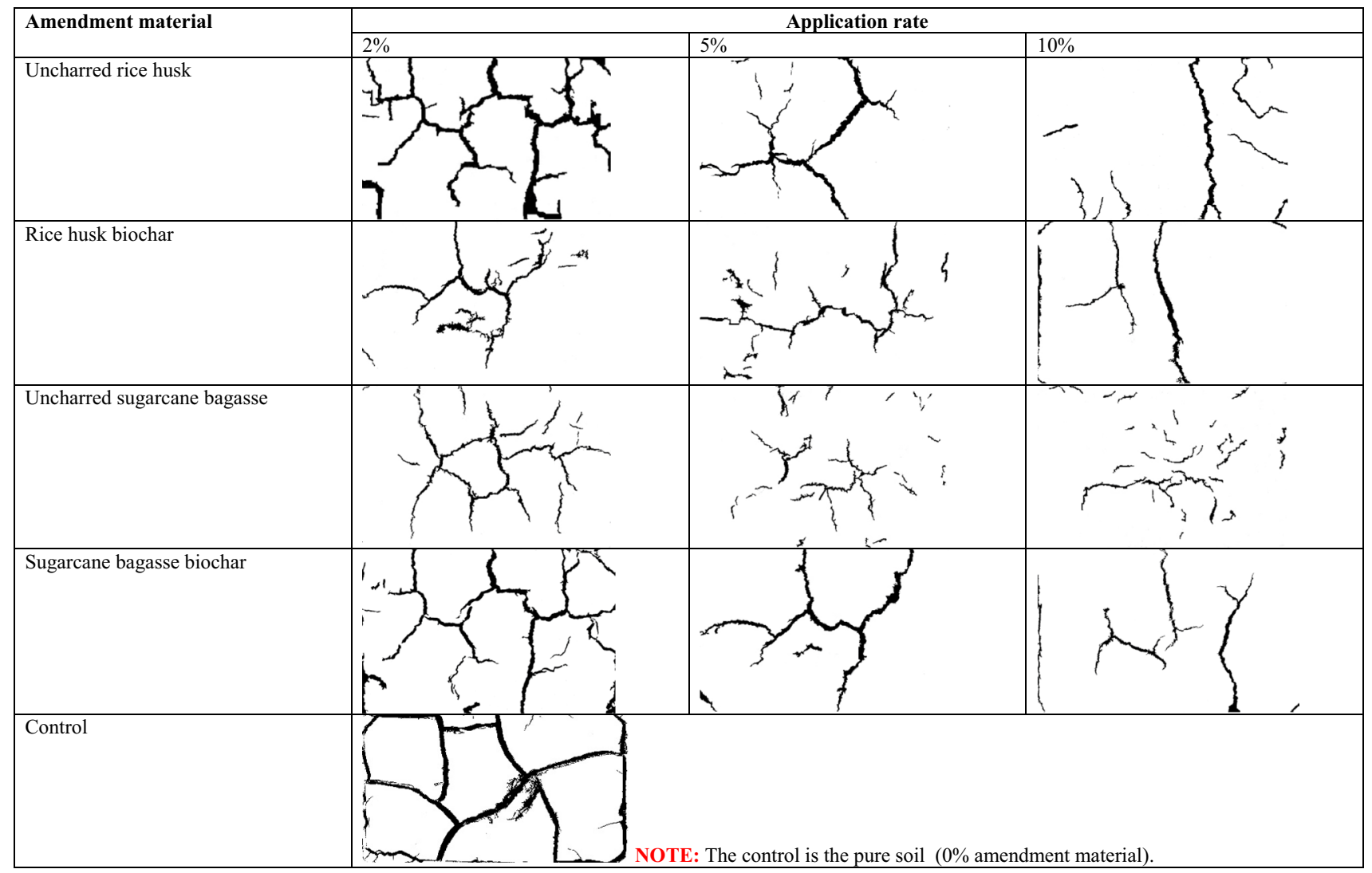

The control is the pure soil ( $0 \%$ amendment material) 
Table 4 Impact of charred and uncharred rice husk and sugarcane bagasse on the on cracking dynamics (fissures dimensions and $\mathrm{CAD}$ ) of the investigated expansive clayey soil

\begin{tabular}{|c|c|c|c|c|}
\hline \multirow[t]{2}{*}{ Amendment material } & \multirow{2}{*}{$\begin{array}{l}\text { Application rate } \\
(\%)\end{array}$} & \multicolumn{2}{|c|}{ Fissures dimensions $(\mathrm{cm})$} & \multirow{2}{*}{$\begin{array}{l}\text { Crack area } \\
\text { density }(\%)\end{array}$} \\
\hline & & $\begin{array}{l}\text { Average crack } \\
\text { length }\end{array}$ & $\begin{array}{l}\text { Average crack } \\
\text { width }\end{array}$ & \\
\hline \multirow[t]{4}{*}{ Uncharred rice husk } & 0 & $11.03^{\mathrm{a}}$ & $0.80^{\mathrm{a}}$ & $12.68^{\mathrm{a}}$ \\
\hline & 2 & $10.63^{\mathrm{a}}$ & $0.70^{\mathrm{ab}}$ & $10.16^{\mathrm{b}}$ \\
\hline & 5 & $10.73^{\mathrm{ab}}$ & $0.47^{\mathrm{bc}}$ & $9.73^{\mathrm{bc}}$ \\
\hline & 10 & $6.70^{\mathrm{b}}$ & $0.27^{\mathrm{c}}$ & $7.61^{\mathrm{c}}$ \\
\hline \multirow[t]{4}{*}{ Rice husk biochar } & 0 & $11.03^{\mathrm{a}}$ & $0.80^{\mathrm{a}}$ & $12.68^{\mathrm{a}}$ \\
\hline & 2 & $10.07^{\mathrm{ab}}$ & $0.43^{\mathrm{b}}$ & $8.87^{\mathrm{b}}$ \\
\hline & 5 & $8.63^{\mathrm{b}}$ & $0.37^{\mathrm{b}}$ & $6.42^{\mathrm{bc}}$ \\
\hline & 10 & $4.83^{\mathrm{c}}$ & $0.27^{\mathrm{b}}$ & $4.84^{\mathrm{c}}$ \\
\hline \multirow[t]{4}{*}{ Uncharred sugarcane bagasse } & 0 & $11.03^{\mathrm{a}}$ & $0.80^{\mathrm{a}}$ & $12.68^{\mathrm{a}}$ \\
\hline & 2 & $8.27^{\mathrm{b}}$ & $0.40^{\mathrm{b}}$ & $8.02^{\mathrm{b}}$ \\
\hline & 5 & $6.70^{\mathrm{bc}}$ & $0.43^{\mathrm{b}}$ & $7.51^{\mathrm{b}}$ \\
\hline & 10 & $4.67^{c}$ & $0.23^{\mathrm{b}}$ & $5.42^{\mathrm{c}}$ \\
\hline \multirow[t]{4}{*}{ Sugarcane bagasse biochar } & 0 & $11.03^{\mathrm{a}}$ & $0.80^{\mathrm{a}}$ & $12.68^{\mathrm{a}}$ \\
\hline & 2 & $8.30^{\mathrm{b}}$ & $0.57^{\mathrm{ab}}$ & $9.00^{\mathrm{b}}$ \\
\hline & 5 & $7.93^{\mathrm{bc}}$ & $0.37^{\mathrm{bc}}$ & $4.79^{c}$ \\
\hline & 10 & $6.17^{\mathrm{c}}$ & $0.27^{\mathrm{c}}$ & $3.82^{\mathrm{c}}$ \\
\hline
\end{tabular}

Means with different letter in the same column are significantly different $(p<0.05)$ husk biochar, $57.26 \%$ for uncharred sugarcane bagasse, and $69.87 \%$ for sugarcane bagasse biochar. Lower CAD value for the amended soils is attributed to the decrease in shrink-swell potential after mixing the soil with rice husk and sugarcane bagasse residues. As discussed earlier, the amendment material has very low shrinkage potential. The addition of very low shrinking materials means reduction in the percentage of high shrinking materials in the mix (Zaffar et al. 2017; Rama Subbarao et al. 2011). Therefore, the percentage of overall crack area in the specimen is reduced as the amendment material application rate increases. This trend is followed for all the amendments. On the other hand, Zong et al. (2014) argue that CAD may be influenced by PI, COLE, and volumetric shrinkage. The lower the soil PI, $\mathrm{COLE}_{\text {core }}$, and VS value is the lower the crack area density of the soil. The application of $10 \%$ sugarcane bagasse biochar resulted in the largest decrease (69.87\% decrease) in CAD values, which is consistent with the largest PI, $\mathrm{COLE}_{\text {core }}$, and VS decrease in sugarcane bagasse-amended soils (Table 2, Figs. 1 and 2).

\section{Fissures' dimensions (crack length and crack width)}

Table 4 also shows the mean values of the cracks' dimensions. The cracks observed in the original soil were wide $(0.80 \mathrm{~cm})$ and long $(11.03 \mathrm{~cm})$. However, shorter and narrower cracks were found in the soil after the application of 2 , 5 , and $10 \%$ charred and uncharred rice husk and sugarcane bagasse, where the crack length was $10 \mathrm{~cm}$ or less and crack width was not more than $0.7 \mathrm{~cm}$. After the application of
$10 \%$ amendments, the crack length decreased by $39.26 \%$ for uncharred rice husk, $56.21 \%$ for rice husk biochar, $57.66 \%$ for uncharred sugarcane bagasse, and $71.51 \%$ for sugarcane bagasse biochar, respectively. On the other hand, crack width decreased by $71.27 \%$ for uncharred sugarcane bagasse and by $66.25 \%$ for charred and uncharred rice husk as well as sugarcane bagasse biochar, respectively. In all, sugarcane bagasse produced a significantly $(p<0.05)$ greater decrease in crack length and crack width than rice husk (Table 4 ).

The values of cracks' dimensions for the amended soil were significantly $(p<0.05)$ lower as compared with the control because of the interaction between organic $\mathrm{C}$ of the amendment material and the soil minerals responsible for soil expansion. According to Zong et al. (2014), the interactions of organic $\mathrm{C}$ with soil minerals change bond strength and surface tension properties of soil, which could affect the formation and prominence of shrinkage cracks. This may probably be because the interaction of $\mathrm{C}$ particles with clay colloids results in the formation of a clay-C complex. The clay-C complexes may influence the behavior of particles at a colloidal level, which cause a significant change at the micro-structural level and affect soil swell-shrinkage properties. So simply put, the decrease in cracks' dimensions may be attributed to the decreased shrink-swell potential in the amended soil.

\section{Saturated water content}

To minimize soil cracking and mitigate damages caused by soil cracks, one should ensure that the soil becomes 
saturated for longer periods of time, so that the soil does not become subjected to crack formation. If the soil retains large amounts of water and becomes saturated for a long period of time, it will take longer for it to dry-out and form desiccation cracks. The effect of charred and uncharred rice husk and sugarcane bagasse on saturated water content of expansive clayey soil is demonstrated in Fig. 3. The original soil had a saturated water content of $46.16 \%$ and the application of various amendment materials brought significant $(p<0.05)$ changes towards the saturated water content of the soil.

Based on Fig. 3, the saturated water increased with an increase in application rate of amendment material into the soil. At the application rate of $10 \%$, the saturated water content of the soil increased by $16.84 \%$ for uncharred rice husk, $27.38 \%$ for charred rice husk, $29.02 \%$ for uncharred sugarcane bagasse, and $30.76 \%$ for sugarcane bagasse biochar, respectively. The incorporated charred and uncharred matter increased the soil's saturated water content, because their decomposed residues, particularly biochar and organic matter, act like a porous sponge that improves water storage capacity of the soil (Zong et al. 2014; Jien and Wang 2013). This allows the farmer to use less water, and worry less much about regular precipitation and maintaining constant soil moisture content. Moreover, since decomposed residues of uncharred and charred matter hold water like a sponge and improve saturated water content of the soil, the soil will not be susceptible to drying and cracking, because it will remain saturated for a prolonged period of time. Furthermore, biochar addition to soils could also minimize soil evaporation losses due to its higher moisture retention and sorption capacity.

It can also be observed from Fig. 3 that soil amended with biochar had a higher moisture storage capacity than the soil incorporated with uncharred matter. $10 \%$ rice husk biochar absorbed $12.67 \%$ more moisture than uncharred rice husk. On the other hand, sugarcane bagasse biochar absorbed $2.49 \%$ more moisture than the uncharred biomass. This is probably because biochar has been subjected to pyrolysis to become a highly porous, fine-grained carbonaceous material (Conte and Laudicina 2017; Liu et al. 2017; Jien and Wang 2013).

\section{Conclusion}

Based on the results of this study, it can be concluded that amendments such as charred and uncharred rice husk and sugarcane bagasse significantly improved the physiochemical as well as the mechanical properties of expansive clayey soil. The amendment materials used improved the desiccation cracking behavior of soil and decreased soil problems induced by desiccation cracking in expansive soil areas by reducing the values of consistency limits, COLEcore, VS, and CAD. In addition to that, an increase in application rate resulted in greater improvements. However, in some instances, $5 \%$ doses of treatments were highly unlikely to cause significant $(p<0.05)$ changes. As observed in the case of PI, fissures' dimensions, and saturated water content, there were no significant $(p<0.05)$ differences between 2 and 5\% application levels. It is, therefore, suggested that $2 \%$ level of amendment application is more preferable than $5 \%$ according to feasibility and economic point of view. However, $10 \%$ application rate still resulted in significantly improved properties than either $2 \%$ or $5 \%$ application rate. It can also be observed from this study that the type of feedstock also has marked effect on soil properties relating to soil expansion. The effect of amendments derived from sugarcane bagasse was more significant $(p<0.05)$ in reducing the swell-shrinkage potential of the soil as compared to the control and rice husk amendments. The biochar and raw crop residues improved the poor physiochemical and mechanical properties of soil by increasing porosity. The results obtained in this study are based on pot incubation experiment and disturbed soil samples. Consequently, fieldscale research needs to be conducted to prove the reliability of the results obtained in this study. Moreover, the field-scale
Fig. 3 Impact of charred and uncharred rice husk and sugarcane bagasse on saturated water content of the investigated expansive clayey soil. The error bars in the figure represent standard error. Different letters above the bars of each treatment indicate significant difference $(p<0.05)$

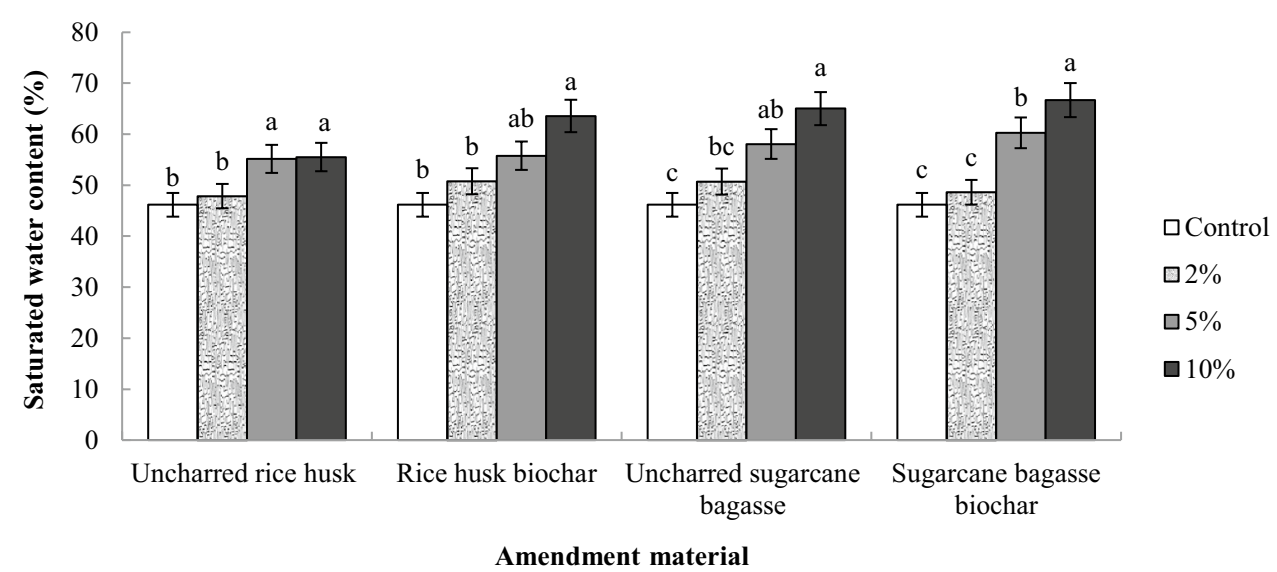

Amendment material 
research can also determine whether crops respond to the observed improvement of physical properties in expansive soils.

Acknowledgements The authors would like to thank the Japan International Cooperation Agency (JICA) for supporting this research through Degree and Internship Program of African Business Education (ABE) Initiative for Youth.

Open Access This article is distributed under the terms of the Creative Commons Attribution 4.0 International License (http://creativeco mmons.org/licenses/by/4.0/), which permits unrestricted use, distribution, and reproduction in any medium, provided you give appropriate credit to the original author(s) and the source, provide a link to the Creative Commons license, and indicate if changes were made.

\section{References}

Andrade FA, Al-Qureshi HA, Hotza D (2011) Measuring the plasticity of clays: a review. Appl Clay Sci 51(1-2):1-7. https://doi. org/10.1016/j.clay.2010.10.028

Arbaaz S, Quddus MA, Hussain MI, Upadhyay G (2015) An experimental study on the atterberg limits of soil around Hussain sagar lake: prospective location for tall structures. Int J Res Eng Technol 4(13):336-339

Bottino FMB, Cunha-Santino IB (2016) Cellulose activity and dissolved organic carbon release from lignocellulose macrophyte derived in four trophic conditions. Braz J Microbiol 47:352-358. https://doi.org/10.1016/j.bjm.2016.01.022

Conte P, Laudicina VA (2017) Mechanisms of organic coating on the surface of a poplar biochar. Curr Org Chem 21:1-7. https://doi. org/10.2174/1385272821666161216122035

Crombie K, Masek O, Sohi SP, Brownsort P, Cross A (2013) The effect of pyrolysis conditions on biochar stability as determined by three methods. Glob Change Biol 5:122-131. https://doi.org/10.1111/ gcbb. 12030

El-gamal E, Saleh ME, Elsokkary I, El-Latif MMA (2017) Comparison between properties of biochar produced by traditional and controlled pyrolysis comparison between properties of biochar produced by traditional and controlled pyrolysis. J Alex Sci Exch 38(3):413-424. https://doi.org/10.21608/asejaiqjsae.2017.3720

Elias EA, Salih AA, Alaily F (2001) Cracking patterns in the vertisols of the Sudan Gezira at the end of dry season. Int Agrophys 15(3):151-155

Grossman RB, Brasher BR, Franzmeier DP, Walker JL (1968) Linear extensibility as calculated from natural-clod bulk density measurements. Soil Sci Soc Am J 32:570-573. https://doi.org/10.2136/ sssaj1968.03615995003200040041x

Husain A, Abad KR, Khan NA (2014) Swelling properties of improved expansive soil by rice husk ash (RHA) and silica fume (SF). Inter Arch Appl Sci Technol 5(3):22-29

Jien SH, Wang CS (2013) Effects of biochar on soil properties and erosion potential in a highly weathered soil. CATENA 110:225-233. https://doi.org/10.1016/j.catena.2013.06.021

Leff B, Ramankutty N, Foley JA (2004) Geographic distribution of major crops across the world. Global Biogeochem Cy 18:33-60. https://doi.org/10.1029/2003GB002108
Liu XH, Han FP, Zhang XC (2012) Effect of biochar on soil aggregates in the loess plateau: results from incubation experiments. Int $\mathrm{J}$ Agric Biol 14(6):975-979

Liu Z, Dugan B, Masiello CA, Gonnermann HM (2017) Biochar particle size, shape, and porosity act together to influence soil water properties. PLoS One 12(6):e0179079. https://doi.org/10.1371/ journal.pone.0179079

Liu Z, Niu W, Chu H, Zhou T, Niu Z (2018) Effect of the carbonization temperature on the properties of biochar produced from the pyrolysis of crop residues. Bio Resour 13(2):3429-3446. https:// doi.org/10.15376/biores.13.2.3429-3446

Mokhtari M, Dehghani M (2012) Swell-shrink behavior of expansive soils, damage and control. Int J Geotech Eng 17:2673-2682

Nwajiaku IM, Olanrewaju JS, Sato K, Tokunari T, Kitano S, Masunaga $\mathrm{T}$ (2018) Change in nutrient composition of biochar from rice husk and sugarcane bagasse at varying pyrolytic temperatures. Int J Recycl Org Waste Agric 7(4):269-276. https://doi.org/10.1007/ s40093-018-0213-y

Pal DK (2016) Cracking clay soils (vertisols): pedology, mineralogy and taxonomy. In: A treatise of Indian and tropical soils. Springer, Cham. https://doi.org/10.1007/978-3-319-49439-5

Quispe I, Navia R, Kahhat R (2017) Energy potential from rice husk through direct combustion and fast pyrolysis: a review. Waste Manag 59:200-210. https://doi.org/10.1016/j.wasma n.2016.10.001

Rama Subbarao GV, Siddartha D, Muralikrishna T, Sailaja KS, Sowmya T (2011) Industrial wastes in soil improvement. ISRN Civ Eng 2011:1-5. https://doi.org/10.5402/2011/138149

Sarkar G, Islam R, Alamgir M, Rokonuzzaman M (2012) Interpretation of rice husk ash on geotechnical properties of cohesive soil. Glob J Res Eng 12(2):1-7

Sowers GF (1979) Introductory soil mechanics and foundations: geotechnical engineering, 4th edn. Macmillan, New York

Taboada MA (2003) Soil shrinkage characteristics in swelling soils. Lecture notes. Dept. Ingen. Agric. Uso Tierra, Facultad de Agronomia. UBA. Buenos Aires, Argentina (March): 1-17

Venegas A, Rigol A, Vidal M (2015) Viability of organic wastes and biochars as amendments for the remediation of heavy metalcontaminated soils. Chemosphere 119:190-198. https://doi. org/10.1016/j.chemosphere.2014.06.009

Wubie AA (2015) Review on vertisol management for the improvement of crop productivity in Ethiopia. Biol Agric Healthc 5(12):92-102

Yuan JH, Xu RK, Zhang H (2011) The forms of alkalis in the biochar produced from crop residues at different temperatures. Bioresour Technol 102(3):3488-3497. https://doi.org/10.1016/j.biort ech.2010.11.018

Zaffar M, Jamil M, Abassi GH, Nafees M, Rafey M, Kamran M (2017) Research article biochar and fly ash role in improving mechanical and physical properties of vertisol. Sarhad J Agric 33(1):151-161. https://doi.org/10.17582/journal.sja/2017.33.1.151.161

Zong Y, Chen D, Lu S (2014) Impact of biochars on swell-shrinkage behavior, mechanical strength, and surface cracking of clayey soil. Plant Nutr Soil Sci 177:920-926. https://doi.org/10.1002/ jpln.201300596

Publisher's Note Springer Nature remains neutral with regard to jurisdictional claims in published maps and institutional affiliations. 